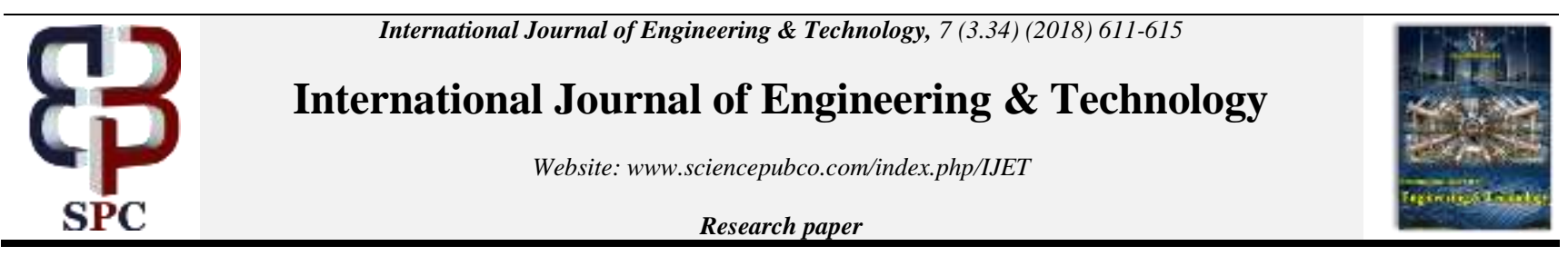

\title{
Moderating Effect of Materialism on the Inaction Inertia Phenomenon
}

\author{
*Seongsoo Lee \\ Department of Counseling Psychology and Social Welfare, Sun Moon University, 70 Sunmoon-ro 221Beon-gil, Tangjeong-myeon, Asan- \\ si, Chungcheongnam-do, 31460, Republic of Korea \\ *Corresponding author E-mail: leessda@sunmoon.ac.kr
}

\begin{abstract}
Background/Objectives: This study aims to investigate whether materialism tendency will act as a moderating variable for the inaction inertia phenomenon.

Methods/Statistical analysis: A total of 121 college students were randomly assigned to 2 (difference in attractiveness condition: large vs. small) $\times 2$ (materialism: high vs. low) mixed design. Respondents read two-part scenario and responded to several questions: manipulation check item to assess perceived attractiveness, some questions related to regret (immediate regret, recalled experienced regret, anticipated inaction regret, anticipated action regret), behavioral intention, and demographics.

Findings: First, the manipulation of the perception of difference in attractiveness (manipulated with price difference) was as the researcher intended. Immediate regret after missing the initial opportunity, recalled experienced regret, and anticipated action regret were found to be varied on the level of materialism. The level of recalled experienced regret, anticipated action regret, and anticipated inaction regret varied according to the difference in attractiveness conditions. The interaction effects of the level of materialism and difference in attractiveness conditions appeared only for anticipated action regret and anticipated inaction regret. Anticipated action regret and inaction regret were found to have a significant effect on behavioral intention regardless of the level of materialism. On the other hand, recalled experienced regret had a significant impact on behavioral intention only in low-materialist group.

Improvements/Applications: This study has theoretical and practical implications from the point of view of how the various kinds of regrets vary according to materialism in the area of inaction inertia effect.
\end{abstract}

Keywords: Inaction inertia, Materialism, Anticipated action regret, Anticipated inaction regret, Experienced regret

\section{Introduction}

Imagine that a grocery shop promotes a $10 \%$ extra discount on regular member discounts for customers signing up for this month. While some consumers know this, they have procrastinated for membership and the time has passed. Will the customer become a member next month? Probably no likely. However, if the consumer does not intend to go to the store in the future at all, it may be, but otherwise it's hard to say it's reasonable to not join. Inaction inertia is a phenomenon that, after missing an earlier attractive opportunity, does not act on a less attractive, but still attractive, subsequent opportunity [1].

Several studies of the inaction inertia effect have referred to various conditions or situations that affect its occurrence and strength. For example, they include avoidability, avoidance cost and the levels of new information about the original opportunities [2], goal-relevance and reversibility [3], information offer sources [4]. It is also important to understand the conditions or situations that affect the occurrence of such inaction inertia phenomena. However, this study attempts to examine how materialism [5] plays a role in weakening or strengthening the inaction inertial effect based on the idea that it is necessary to find out what role the individual's chronic tendency plays in the expression of the effect.

The conceptualization and measurement of materialism varies slightly from researcher to researcher. However, Richins \& Dawson [5] reviewed various previous studies to define materialism centered on three factors. They are acquisition centrality (The possession and acquisition of materials itself constitutes life and determines action), acquisition as the pursuit of happiness (Life satisfaction comes from the acquisition process of possessions), and possession defined success (The criterion of success is the quantity and quality of possessions). In this conceptualization of materialism, a person with a high materialistic tendency tends to value the acquisition of material and the means to acquire it, and to value ownership and acquisition higher than human relationships or other goals in life. Also, the higher the value of materialism, the lower self-control in the process of social comparison, and the tendency to rely more on product purchases to remove uncertainty and self-doubt [6]. Given the nature of such materialism, the higher the materialist propensity, the weaker the inaction inertia effect. Therefore, this study aims to investigate whether materialism tendency will act as a moderating variable for the inaction inertia phenomenon.

\section{Theoretical Background}

\subsection{Inaction Inertia Effect}

The general idea is that in a purchasing situation with two alternatives, people will choose between alternative A and B. But 
there is another alternative: it does not do the selection itself. If you apply this idea to repetitive selection behaviors, you may repeat actions that take something, but you may repeat actions that do nothing. Research on repetitive behaviors was mainly concerned with how and why taking something was repetitive. On the other hand, Tykocinski et al. [1] have been interested in the phenomenon that no action has taken place since there was no cost at the beginning, and this phenomenon was conceptualized as a inaction inertia effect. This effect is a phenomenon that when a consumer realizes that she or he missed the initial, attractive action opportunity, she or he forgoes the subsequent opportunity, which is relatively less but still attractive than the previous opportunity. There may be many variables that need to be taken into account when developing a framework to understand the inaction inertia on subsequent opportunities. The primary consideration of Tykocinski et al. [1] was the initial attractiveness of behavioral opportunities. It is believed that the initial forgone or missed opportunity is usually perceived more attractive than the subsequent opportunity. So, by Tykocinski et al. [1, p.794], "inaction inertia occurs when bypassing an initial action opportunity has the effect of decreasing the likelihood that subsequent similar action opportunities will be taken." In other words, it is a phenomenon in which the likelihood of action is reduced in a similar but relatively less attractive behavioral opportunity after missing an initial, attractive action opportunity to gain.

Previous studies on inaction inertia refer to the anticipated counterfactual regret as a major predictor of inaction inertia [2]. An anticipated counterfactual regret is a regret that is likely to be experienced as a result of a specific event in the future, assuming that the particular event that has not yet occurred is actually occurring in the future. However, people may regret after some action, or regret without doing so, Tykocinski and Pittman [1] did not clarify this. People also regret looking back on past actions. All of these regrets will comprehensively affect future behavior choices. It is difficult to find such a variety of regrets in one study except for the study of Sevdalis, Harvey \& Yip [7] and Lee [8].

Since the concept of inaction inertia phenomena has been presented, a number of studies have been conducted on this. The studies can be summarized into two major groups. One is to identify the conditions or circumstances under which the phenomenon occurs, and the other is which individual difference moderates the magnitude of the phenomenon. In the latter, individual differences such as consumer state and action orientation [9], consideration of future consequences [10], \& regulatory focus [8] have been found to moderate the inaction inertia effect.

\subsection{The Moderation of Materialism}

The conceptualization and measurement of materialism differs slightly from researcher to researcher. Daun [11] defined materialism in terms of lifestyle as a lifestyle in which high level of material consumption is a goal or serves a set of plans. Belk [12] describes materialism as a trait, attaching possession of the substance itself and pursuing happiness through discretionary consumption. Belk argues that the higher the level of materialism is, the more likely it is that possession is central to the individual's life and serves as the greatest cause of satisfaction-dissatisfaction. $\mathrm{He}$ asserted that materialism consists of three sub-attributes: possessiveness, envy, and nongenerosity. Possessiveness refers to the tendency to retain control or ownership of own possessions. Envy means discomfort or malice of someone else having happiness, reputation, reputation or anything else desirable. Finally, nongenerosity means that they are not willing to give their possessions to others or to share them with others.

On the other hand, Richins and Dawson [5] summarized the factors that were relatively frequently mentioned in various prior researches in the field of religion, social criticism, and psychology in conceptualizing materialism and then argued that it is appropriate to conceptualize materialism as a value according to such sub-concepts. The first of the sub-concepts is to give meaning to acquisition itself, which is a tendency to regard the acquisition process of possessions as the center of life, meaning the ownership and acquisition of material constitute life and determine behavior. Second, acquisition as the pursuit of happiness means that personal happiness or satisfaction of life comes from the possession itself or the acquisition process of possessions. Lastly, possession defined success means that the criterion of success for the self and others is in the quantity and quality of the possessions.

According to the above discussion of the concept of materialism, people with high materialism tend to exhibit some other characteristics than those with low propensity. First, the mention of Daun [11] that materialism is a goal and a plan, people with a high materialism tendency is highly valued in the acquisition of the material itself and in the means of acquisition, and considers the possession and acquisition of the material higher than human relationships or other goals of life. Second, a person with a high materialism tendency tends to pursue complex life rather than materially monotonous life [13]. Third, people with a higher materialism tend to feel dissatisfied in life than people with lower ones. Because, as the law of the marginal utility of economics explains, the satisfaction of the possessions of the material diminishes over time, instead inviting the possession of other material [14].

The reason why materialistic values are formed is due to the uncertainty of the status quo and self-doubt [15], and therefore people seek to reach happiness through the pursuit of material values. Materialism is a state of mind primarily concerned with making and spending money [16], and Vargas and Yoon [17] mentioned three paths in which material values develop. First, it is due to the modeling of materialists and exposure to such values. Second, people become materialists to improve their self-worth and their ability to cope creatively with challenges, and to offset their worries and anxieties about safety in an unpredictable world. Third, it is based on social comparison. Due to this materialistic development path, for example, the higher the value of materialism, the lower the eco-friendly post-purchase behavior [18], and the greater conspicuous consumption and overconsumption [19]. This consumption phenomenon is because hedonic shopping value (versus utilitarian shopping value) and experiential attributes (versus search attributes) is considered to be more important when purchasing product. Taken together, these findings and discussions reveal that the higher the value of materialism, the lower self-control in the process of social comparison, and the greater dependence on product purchase to remove uncertainty and self-doubt. The more we focus on a particular goal, the lower the individual's attention control and therefore the less self-regulating ability [6]. Based on these discussions, when the materialistic values are activated, our selfcontrol is lowered and the impulse buying tendency, which is a response to the stimulation due to the lowered self-control, is likely to increase. In fact, some previous studies have already demonstrated the impact of materialism on impulse buying [18]. As a result, the higher the level of materialism, the lower the inaction inertia effect is expected to be.

\section{Research Method}

\subsection{Participants and Design}

A total of 121 college students were randomly assigned to 2 (difference in attractiveness: large vs. small) $\times 2$ (materialism: high vs. low) mixed design. The mean age of the subjects was 22.1 years $(\mathrm{SD}=1.48)$, the minimum age was 20 years, and the maximum age was 26 years. 


\subsection{Experimental Material and Procedure}

As with previous studies on inaction inertia, this study also used scenario techniques. The product in the scenario was formal dress. College students usually do not have formal dresses. However, they are at the beginning of adulthood, so sometimes they are considering purchasing a formal dress because they often experience situations that require it. Therefore, it was expected that the scenario using the formal dress was easy to induce the immersion of the respondents

The scenario was divided into two parts. The first part is as follows: Earlier in the month, respondents found that a clothing store, not far from home through an advertising flyer, was offering special discounts in celebration of the 5th anniversary of the opening. Since long ago you used to think you need to buy a suit. There were several brands of suits on the flyer. Among these products, there was a new product of this season, and a product that fits your heart in color and design. In addition, it was to discount the normal price of $300,000 \mathrm{KRW}$ to $240,000 \mathrm{KRW}$ (Small difference condition, 20\% off; Large difference condition, $50 \%$ off). Looking at the special sale period on the flyer, you had five more days left. However, during that period you could not go to the store, and the special discount period had passed with no purchase of the formal dress. Respondents read this scenario and responded to manipulation check question and Immediate experienced regret question.

The second part was the same for all respondents, and the content is as follows: Today, you went to a department store and found out that the new formal dress, which you saw the same as last month's ad flyer, is being sold for 270,000 won (10\% off). After reading this, the respondents responded to the Recalled experienced regret, regret when you buy (Anticipated action regret), regret when you not buy (Anticipated inaction regret), Purchase intention, and some demographic questions.

\subsection{Measures}

In order to check whether the respondents perceived difference in attractiveness of the price discount differently, the respondents were asked to answer the question "How attractive do you think the opportunity of purchasing a $150,000 \mathrm{KRW}$ suit is attractive to you?" (7-point scale, 1 = didn't feel that much, 7 = felt that much). To find out how much you experience Immediate regret about missing an attractive buying opportunity (50\% or $20 \%$ discount), the respondents were asked the question "How much do you regret not buying a 150,000 KRW [240,000 KRW] suit in this case?" (7point scale, $1=$ no regret, 7 = very much regret).
In order to measure the Recalled experienced regret for missing the attractive initial opportunity when facing a subsequent opportunity, the respondents were asked the following question: "How much do you regret that you did not buy a $150,000 \mathrm{KRW}$ suit last month after finding out that it sells for 270,000 KRW today?" (7-point scale, $1=$ no regret, $7=$ very much regret).

In order to see the Anticipated action regret (when buying) and the Anticipated inaction regret (when not buying) in subsequent opportunity, the respondents were asked the following question: "How much do you regret if you buy (or do not buy) the suit at 270,000 KRW?" (7-point scale, 1 = no regret, 7 = very much regret).

In order to determine the purchase intention at the new opportunity (10\% off purchase), the respondents were asked the following question: "How much do you intend to buy the suit at 270,000 KRW?" (7-point scale, 1 = have no idea what to buy, 7 = will buy it).

Materialism was measured using the scale provided by Richins\& Dawson [5]. 7-point scale was used $(1=$ strongly disagree, $7=$ strongly agree). Cronbach's $\alpha$ was $.852(\mathrm{M}=4.263, \mathrm{SD}=.833)$. In this study, the summed average of materialism score was used. The higher the score, the higher the materialistic tendency.

\section{Results}

\subsection{Manipulation Check and Relationships among Variables}

In order to confirm whether the manipulation of perception of difference in attractiveness (manipulated with price difference) appeared as intended by the researchers, independent t-test were conducted. Respondents in large difference condition were significantly perceived in the attractiveness difference between the initial opportunity and the second opportunity compared to those in small difference condition, $\mathrm{t}(119)=-3.802, \mathrm{p}<.001$. Large difference condition for discount attractiveness was $\mathrm{M}=5.92$ (SD $=1.04)$ and small difference condition was $\mathrm{M}=4.98(\mathrm{SD}=1.61)$. [Table 1] shows the overall correlation of the main variables used in the study. The greater the difference in attractiveness, the greater the level of Recalled experienced regret (RER; $r=.252, p$ $<.001$ ) and Anticipated action regret (AAR; $\mathrm{r}=.195, \mathrm{p}<.05$ ). The correlation between purchasing intention and AAR $(r=-.430$, $\mathrm{p}<.001)$ and between purchase intention and AIR $(\mathrm{r}=.537, \mathrm{p}<$ .001) showed an opposite relationship at a remarkable level. However, the correlation between AAR and AIR $(r=-.192, p<$ $.05)$ is significant, but it is difficult to say that the size is large.

Table 1: Correlations among the variables used in the study

\begin{tabular}{|c|c|c|c|c|c|c|}
\hline & DA & IER & RER & AAR & AIR & PI \\
\hline Difference in attractiveness (DA) & 1 & & & & & \\
\hline Immediate experienced regret (IER) & .110 & 1 & & & & \\
\hline Recalled experienced regret (RER) & $.252^{* *}$ & $.466^{* * *}$ & 1 & & & \\
\hline Anticipated action regret (AAR) & $.195^{*}$ & $.207^{*}$ & $.427^{* * * *}$ & 1 & & \\
\hline Anticipated inaction regret (AIR) & -.142 & $.310^{* *}$ & .050 & $-.192^{*}$ & 1 & \\
\hline Purchase intention (PI) & -.126 & .156 & .049 & $-.430^{* * *}$ & $.537^{* * * *}$ & 1 \\
\hline Materialism & .009 & $.354^{* * *}$ & $.244^{* *}$ & .167 & .060 & .022 \\
\hline
\end{tabular}

$※$ Coded as 1 if the attractiveness difference is small, and 2 if it is large.

$* \mathrm{p}<.05, * * \mathrm{p}<.01, * * * \mathrm{p}<.001$

\subsection{Difference in Inaction Inertia Effect According to Materialism Tendency}

We examined whether the difference of various regrets (immediate regret after missing the initial opportunity, recalled experienced regret, anticipated action regret, anticipated inaction regret) due to the difference in attractiveness condition is moderated by the individual difference variable of materialism. For this, the SPSS Process macro model 1 developed by Hayes was used.

\subsubsection{Immediate Experienced Regret after Missing the Initial Opportunity}

First, in regression analysis on immediate experienced regret after missing initial opportunity, regression model was significant $\left(\mathrm{R}^{2}=.140, \mathrm{~F}(3,117)=8.254, \mathrm{p}<.001\right)$. Materialism was found to have a significant effect on immediate regret $(\mathrm{B}=.652, \mathrm{SE}=.183$, $t(117)=3.568, p<.001)$. However, the main effect of the difference in attractiveness condition and the interaction effect of the two 
independent variables did not have a significant effect on immediate regret after missing the initial opportunity.

\subsubsection{Recalled Experienced Regret}

Second, in regression analysis on recalled experienced regret for missing attractive initial opportunities after encountering subsequent purchase opportunity, regression model was significant $\left(\mathrm{R}^{2}=.129, \mathrm{~F}(3,117)=7.803, \mathrm{p}<.001\right)$. The main effects of materialism $(\mathrm{B}=.433, \mathrm{SE}=.164, \mathrm{t}(117)=2.646, \mathrm{p}<.01)$ and the difference in attractiveness condition $(\mathrm{B}=.755, \mathrm{SE}=.266$, $\mathrm{t}(117)=2.835, \mathrm{p}<.01)$ were significant. However, the interaction effect of the two variables was not significant.

\subsubsection{Anticipated Action Regret}

Third, in moderated regression analysis on anticipated action regret, regression model was significant $\left(\mathrm{R}^{2}=.088, \quad \mathrm{~F}(3\right.$, 117) $=4.038, p<.01)$. The main effect of the difference in attractiveness condition was significant $(B=.574, \quad S E=.267$, $\mathrm{t}(117)=2.154, \mathrm{p}<.05)$. However, the main effect of materialism $(\mathrm{B}=.283, \mathrm{SE}=.153, \mathrm{t}(117)=1.854, \mathrm{p}=.066)$ and the interaction effect of the two independent variables $(\mathrm{B}=.541, \mathrm{SE}=.305$, $\mathrm{t}(117)=1.771, \mathrm{p}=.079)$ were marginally significant. [Figure 1] shows the interaction effect on anticipated action regret.

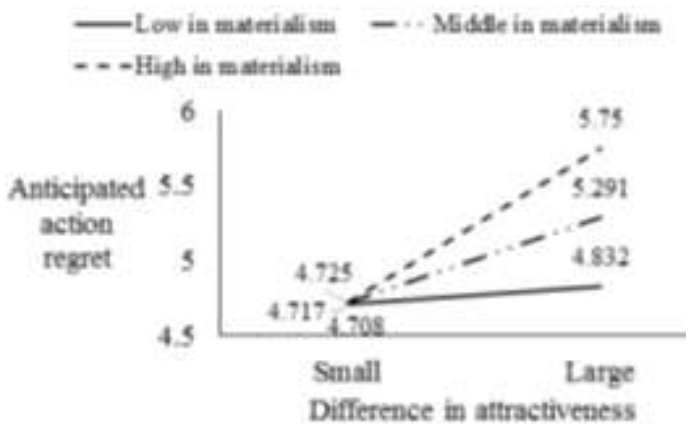

Figure 1: Interaction of materialism and difference in attractiveness on anticipated action regret

\subsubsection{Anticipated Inaction Regret}

Fourth, in moderated regression analysis on anticipated inaction regret, regression model was significant $\left(\mathrm{R}^{2}=.083, \mathrm{~F}(3\right.$, $117)=3.114, \mathrm{p}<.05)$. The main effect of materialism and difference in attractiveness condition were not significant. However, the interaction of the two independent variables was significant $(\mathrm{B}=-$ $.816, \mathrm{SE}=.298, \mathrm{t}(117)=-2.734, \mathrm{p}<.01)$. [Figure 2] shows the interaction effect on anticipated action regret.

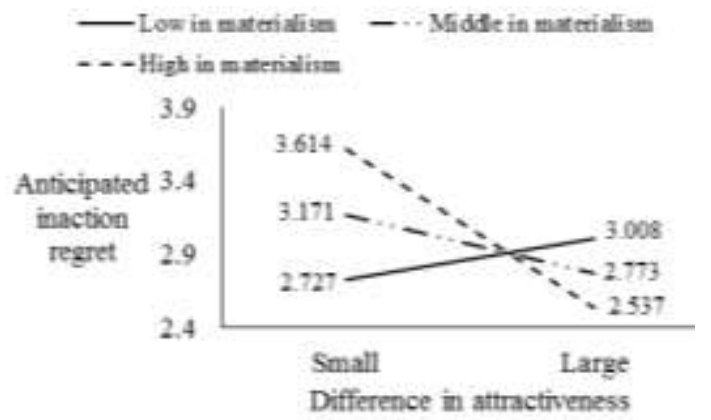

Figure 2: Interaction of materialism and difference in attractiveness on anticipated inaction regret

\subsubsection{Relative Influences of Difference in Attractiveness and Various Regrets by Materialistic Level}

A multiple regression analysis was conducted to examine relative influences of difference in attractiveness (or price difference) and four regrets on purchase intention according to the level of materialism. The regression model of the low materialism group $\left[\mathrm{R}^{2}=.450, \mathrm{~F}(4,54)=11.067, \mathrm{p}<.001\right]$ and the regression model of the high materialism group $\left[\mathrm{R}^{2}=.475, \mathrm{~F}(4,57)=12.890, \mathrm{p}<.001\right]$ were respectively significant. The results of the regression coefficients for each group are shown in [Table 2] and [Table 3]. As can be seen from the two tables, regardless of the level of materialism, action regret (negative influence) and inaction regret (positive influence) had a significant effect on purchase intention. On the other hand, it can be seen that the recalled regret has a significant positive effect only on the group with low materialism level.

Table 2: Regression analysis results in low materialist groups

\begin{tabular}{|l|l|l|l|l|}
\hline \multirow{2}{*}{ Model } & \multicolumn{2}{|l|}{$\begin{array}{l}\text { Non-standardized } \\
\text { coefficient }\end{array}$} & $\begin{array}{l}\text { Standardized } \\
\text { coefficient }\end{array}$ & \multirow{2}{*}{$\mathrm{t}$} \\
\cline { 2 - 4 } & $\mathrm{B}$ & Standard error & Beta & \\
\hline RER & .281 & .114 & .275 & $2.474^{*}$ \\
\hline AAR & -.332 & .131 & -.294 & $-2.535^{*}$ \\
\hline AIR & .540 & .123 & .482 & $4.371^{* * *}$ \\
\hline DA & -.486 & .309 & -.161 & -1.575 \\
\hline
\end{tabular}

Note. RER: recalled experienced regret; AAR: anticipated action regret; AIR: anticipated inaction regret; DA: difference in attractiveness; $* \mathrm{p}<$ $.05, * * * \mathrm{p}<.001$

Table 3: Regression analysis results in high materialist groups

\begin{tabular}{|l|l|l|l|l|}
\hline \multirow{2}{*}{ Model } & \multicolumn{2}{|l|}{$\begin{array}{l}\text { Non-standardized } \\
\text { coefficient }\end{array}$} & $\begin{array}{l}\text { Standardized } \\
\text { coefficient }\end{array}$ & \multirow{2}{*}{$\mathrm{t}$} \\
\cline { 2 - 5 } & $\mathrm{B}$ & $\begin{array}{l}\text { Standard } \\
\text { error }\end{array}$ & Beta & \\
\hline RER & .141 & .134 & .121 & 1.052 \\
\hline AAR & -.599 & .122 & -.555 & $-4.926^{* * *}$ \\
\hline AIR & .615 & .130 & .496 & $4.720^{* * *}$ \\
\hline DA & .559 & .400 & .160 & 1.396 \\
\hline
\end{tabular}

Note. RER: recalled experienced regret; AAR: anticipated action regret; AIR: anticipated inaction regret; DA: difference in attractiveness; $* * * \mathrm{p}<$ .001

\section{Conclusion}

This study examined how the inaction inertia phenomenon varies according to the materialism tendency. Specifically, we tried to see how the various kinds of regrets and purchase intention vary according to materialism and difference in attractiveness. The results of the analysis show that the immediate regret experienced after missing the initial opportunity did not differ according to the condition of difference in attractiveness but it was found to be different according to the level of materialism. In other words, the higher the level of materialism, the greater the IER. The higher the level of materialism and the greater the difference in attractiveness between the initial and subsequent opportunities, the higher the level of recalled experienced regret. The anticipated action regret (ie, regrets expected when purchasing on the second occasion) was significant only for the difference in attractiveness. Nonetheless, the interaction effects of materialism and difference in attractiveness on anticipated action regret were marginally significant. In other words, for people with low levels of materialism, the level of anticipated action regret did not show any significant difference, regardless of whether the difference in attractiveness was large or small. However, in the case of people with large materialism tendency, the anticipated action regret level was also high when the difference in attractiveness was large compared to the small difference. A similar pattern was also observed for the anticipated inaction regret. In other words, in the case of people with low level of materialism, there was no significant difference in the level of anticipated inaction regret, whether the attractiveness difference was large or small. However, in the case of those with a high tendency, the anticipated inaction regret level was also low when the attractiveness difference was 
large compared to the small difference.

The relative influences of difference in attractiveness and different regrets on purchase intention were found to be different according to the level of materialism. In the case of high materialism (compared to the low case), the recalled experienced regret had a significant effect on purchase intention. (This was not the case when high.) Action regret and inaction regret, regardless of whether materialism is high or low, were found to have a significant effect on purchase intention. However, beta coefficients showed that action regret had a greater effect on purchase intention when materialism was high (as compared to low).

These results have several implications. First, the greater the difference in attractiveness between the initial opportunity and the subsequent opportunity, the greater the experienced regret and the anticipated action regret. On the other hand, as in the previous study, it was observed that the effect of anticipated action regret and inaction regret was significant for purchase intention. Third, it was observed that the effect of regret type on purchase intention was different according to the size of materialist propensity. In other words, for those with low materialism the recalled experienced regrets had a significant impact on purchase intent, but not for those with high materialism. Although both the anticipated action regret and anticipated inaction regret had a significant impact on purchase intention, the magnitude of the relative effects varied depending on the level of materialism. In other words, the negative effect of anticipated action regret on purchasing intention was greater for people with higher materialism (compared to the lower ones). On the other hand, the effect of anticipated inaction regret on purchase intention was greater for people with low materialism (compared to high people).

In a sense, the inaction inertia effect can be a negative consequence for both the firm and the consumer. The promotion policies of enterprises are bound to change at any time. However, if the inaction inertia effect occurs, firms will no longer be able to sell, and consumers will not enjoy better benefits. The results of this study show that people who are lower than those with high materialism are more likely to make purchases at subsequent opportunities. Because the relative impact of anticipated action regret levels is greater than anticipated action regret in people with low materialism. Therefore, it is expected that if people who do not believe that the possession of the material is happy are communicating about rational consumption to people with low materialism, their purchasing will be further improved.

There are some limitations in generalizing the results of this study. First of all, this study shows that the time interval between the initial opportunity and the subsequent opportunity is less than one month (implicitly). We can see that the inaction inertia effect can vary depending on how the time interval varies. Second, this study manipulated the attractiveness of the product by reduction in price. Attractiveness levels may be manipulated in ways other than price: Other attributes of the product or gift level etc.. Third, even if we manipulate the attractiveness level by price, the level of attractiveness perception may be different depending on the product type. Future studies may need to consider these limitations.

\section{References}

[1] Tykocinski, O. E., Pittman, T. S., \& Tuttle, E. E.(1995). Inaction Inertia: Foregoing Future Benefits as a Result of an Initial Failure to Act. Journal of Personality and Social Psychology, 68(5), 793803.

[2] Tykocinski, O. E. \& Pittman, T. S. (1998). The Consequences of Doing Nothing: Inaction Inertia as Avoidance of Anticipated Counterfactual Regret. Journal of Personality and Social Psychology, 75(3), 607-616.

[3] Patrick, V. M., Lancellotti, M. P., \&Demello, G.(2009). Coping with non-purchase: Managing the Stress of Inaction Regret. Journal of Consumer Psychology, 19, 463-472.

[4] Butler, A. \&Highhouse, S.(2000). Deciding to Sell: The Effect of Prior Inaction and Offer Source. Journal of Economic Psychology, 21, 223-232.

[5] Richins, M. L. \& Dawson, S. (1992). A Consumer Values Orientation for Materialism and Its Measurement: Scale Development and Validation. Journal of Consumer Research, 19(December), 303-315.

[6] Rueda, M. R., Posner, M. I., \&Rothbart, M. K.(2004). Attentional Control and Self-Regulation. in R. F. Baumeister\& K. D. Vohs (ed.), Handbook of Self-Regulation: Research, Theory, and Applications. 283-300, NY: The Guilford Press.

[7] Sevdalis, N., Harvey, N., \& Yip, M. (2006). Regret Triggers Inaction Inertia -But which Regret and How? British Journal of Social Psychology, 45, 839-853.

[8] Lee, S. (2015). The Moderating Effect of Regulatory Focus on the Effect of Inaction Inertia: The Mediating Effect of Anticipated Regret and Satisfaction. Indian Journal of Science and Technology, $8(19)$.

[9] Van Putten, M., Zeelenberg, M., \& Van Dijk, E.(2009). Dealing with Missed Opportunities: Action vs. State Orientation Moderates Inaction Inertia. Journal of Experimental Social Psychology, 45, 808-815.

[10] Lee, S. (2013). The Inaction Inertia Effect: The Moderating Effect of the Consideration of Future Consequences. Journal of Next Generation Information Technology, 4(8), 154-161.

[11] Daun, A.(1983). The Materialistic Life-style: Some SocioPsychologistic Aspects in Consumer Behavior. NY: The Dryden Press.

[12] Belk, R.(1985). Materialism: Trait Aspects of Living in the Material World. Journal of Consumer Research, 12, 265-280.

[13] Inglehert, R.(1981). Post-Materialism in an Environment of Insecurity. American Political Science Review, 75, 880-900.

[14] Richins, M. L.(1987). Media, Materialism and Human Happiness. Advances in Consumer Research, 14, 352-356.

[15] Kasser, T. \&Kanner, A. D.(2003). Psychology and Consumer Culture: The Struggle for a Good Life in a Materialistic World. Washington, D.C.: American Psychological Association.

[16] Rassuli, K. M. \& Hollander, S. C.(1986). Desire-Induced, Innate, Insatiable? Journal of Macro Marketing, 6(Fall), 4-24

[17] Vargas, P. \& Yoon, S.(2006). On the Psychology of Materialism: Wanting Things, Having Things, and Being Happy. Advertising and Society Review, 7(1)

[18] Tilikidou, I. and Delistavrou, A. (2004). The Influence of the Materialistic Values on Consumers' Pro-Envrionmental PostPurchase Behavior. In: Cron, W.L. and Low, G.S. (Eds.) Marketing Theory and Applications, Proceedings of the 2004 American Marketing Association Winter Educators' Conference, vol. 15, Chicago IL., A.M.A., pp. 42-49.

[19] Vohra, A. V. (2016). Materialism, Impulse Buying and Conspicuous Consumption: A Qualitative Research. Global Business Review, 17(1), 51-67. 